\title{
A hipótese pigmentocrática
}

\section{The pigmentocratic hypothesis}

\section{Benno Warken Alves ${ }^{\mathrm{a}}$}

TeLLES, Edward. The Project on Ethnicity and Race in Latin America (PERLA). Pigmentocracies: ethnicity, race and color in Latin America. Chapel Hill: The University of North Carolina Press, 2014. 297 p.

Abordagem transnacional e dados originais fazem de Pigmentocracies: ethnicity, race and color in Latin America um marco necessário - e, a partir de agora, referência incontornável - nos debates sobre desigualdades raciais e étnicas na América Latina. Destaca-se, na pesquisa, uma inovação que produziu resultados surpreendentes: o emprego simultâneo de vários métodos de categorização étnico-racial, incluindo a controversa paleta de cores, a qual provavelmente figurará no centro de futuras discussões técnicas, científicas e políticas continente afora.

O resultados reunidos no livro têm potencial para revolucionar o modo como usualmente se relaciona raça e desigualdade nos três países hispano-falantes pesquisados, quais sejam, Colômbia, México e Peru. Quanto ao Brasil, o quarto país incluído na pesquisa, o impacto do emprego da paleta é mais circunscrito, embora nisso esteja também seu grande valor: os dados, em geral, corroboram proposições clássicas dos cientistas sociais brasileiros e estrangeiros sobre o país, indicando que as pesquisas sobre raça, racismo e desigualdades raciais vêm sendo desenvolvidas sobre bases sólidas.

Pigmentocracies apresenta os resultados do Project on Race and Ethnicity in Latin America (PERLA), que reuniu sob a coordenação de Edward Telles quatro equipes nacionais de pesquisadores. O projeto iniciou-se em 2010 e tomou cinco anos de trabalho. Foi desenhado, testado e aplicado um survey com amostras representativas em cada um dos quatro países, contando com um conjunto principal de questões em comum e algumas adaptações locais. São, sobretudo, os novos dados produzidos no marco do PERLA que alimentam as boas análises do livro.

A necessidade de produzir esses dados inéditos foi estabelecida a partir de uma apreciação crítica dos dados disponíveis, muito deficientes - à exceção do caso brasileiro - em termos de composição étnico-racial da população e das

a Bacharel em Ciências Sociais pela UFPR (2011) e mestre em Sociologia pela Universidade de São Paulo (2014). Atualmente, é doutorando em Sociologia na mesma instituição. 
desigualdades correspondentes. O problema é que os censos e as estatísticas oficiais, fortemente vinculados a tradições de formação nacional, tanto forjam como refletem o poder de ideologias de integração nacional, como a mestizaje e a democracia racial, ainda que não se possa afirmar que as categorias utilizadas nos censos sejam apenas determinadas ideologicamente (cf. LovEMAN, 2014).

O caso do México é ilustrativo. No país, afirmam os autores, a mestiçagem ainda é uma narrativa de integração nacional virtualmente incontestada, na qual diferenças étnico-raciais não têm lugar. Entre 1930 e 1990, o censo mexicano apenas permitia identificá-las por meio de uma questão sobre línguas indígenas; somente em 2000, seguindo diretrizes internacionais, adotou-se uma questão de auto-identificação como membro de algum grupo indígena, que foi mantida, ainda que com alterações, no último censo de 2010. Outros grupos, como os afrodescendentes, seguem sem ser identificados. Na imagem formada pelas estatísticas oficiais, ficam evidentes as desigualdades entre os indígenas e o resto da população, porém é impossível saber que outras categorias podem descrever bem as grandes desigualdades sociais mexicanas.

Outra boa ilustração, o censo colombiano ficou entre 1918 e 1993 sem qualquer questão que permitisse identificar os afrodescendentes, hoje cerca de 20\% da população, segundo dados oficiais. No Peru, a situação se aproxima da mexicana: desde 1940, o censo apresenta apenas a questão sobre línguas indígenas, o que permaneceu até o último realizado, em 2007. São grandes tais lacunas nos países latino-americanos, que não produziram de modo consistente dados sobre a composição étnico-racial de suas populações. Sem esses dados, evidentemente, não é possível chegar a um acordo básico sobre a existência, a forma e a dimensão das desigualdades raciais - quanto menos começar a discuti-las em bases científicas. As novas informações decorrentes do PERLA permitem elevar a um novo patamar os debates sobre desigualdade, raça e etnia nesses países.

A depender de como os movimentos sociais e os governos utilizarem as descobertas sintetizadas em Pigmentocracies, as pesquisas oficiais poderão ser aprimoradas e oferecer, no futuro, imagens mais precisas e plurais dessas sociedades. Uma suposição que sai fortemente abalada é a naturalidade com que o tipo nacional mestizo é deduzido do parco reconhecimento oficial de minorias para além da indígena, especialmente no México e no Peru. Uma das conclusões que perpassa todas as análises nacionais do livro é que o modo de mensurar "raça" e "etnia", ou seja, a pergunta que se utiliza para coletar essas informações, altera profundamente os resultados. Por isso, o questionário inclui diversas questões alternativas. No Peru, os resultados do PERLA mostram que a proporção de 
indígenas na população pode variar de $4,7 \%$, quando a questão proposta é a auto-identificação (no caso, como "indígena"), a 23,3\% quando se pergunta se o indivíduo se considera de origem quechua, aymara ou indígena da Amazônia (pergunta que vem sendo utilizada mais recentemente em surveys amostrais oficiais); podendo subir a 40\% se considerado como indígena o indivíduo que declara possuir qualquer ancestral indígena. Na medida em que "indígena" é uma categoria muito estigmatizada, apresentá-la de modo taxativo como uma opção de auto-identificação leva a subestimar em muito sua proporção na população. Formulada de outro modo, a questão levou muitos indivíduos que a princípio se declararam mestizos a se recolocarem como quechua ou aymara nas perguntas sucessivas do questionário do PERLA, como sugerem os dados. A formulação da pergunta altera profundamente o modo como se concebe o mainstream nacional, a imagem que se tem do "povo".

Entre as medidas alternativas de classificação racial destaca-se a paleta de cores. Trata-se de um gradiente, elaborado a partir do estudo de fotografias, que cobre as variações de cor da pele mais frequentes. O entrevistador, antes da entrevista e sem revelar ao entrevistado, procurou classificá-lo, com base na sua cor de pele facial, em um dos 11 tons da paleta. A técnica já foi usada em pesquisas menores, sobretudo nos Estados Unidos, mas é novidade em um estudo da amplitude do PERLA, bem como na América Latina.

É verdade que seu emprego pode ser contestado. A elaboração e a aplicação da técnica foram coordenadas com competência por Telles e sua equipe, sendo a paleta não mais do que um modo engenhoso de operacionalizar hipóteses acerca da relação entre classificação racial, "cor” e desigualdade. Em mãos menos preparadas, entretanto, bem como aos olhos da opinião pública, a paleta poderia assumir o sentido de uma classificação racial naturalista. Isto é, a "cor" assim medida poderia acabar sendo interpretada como indicador imediato de uma noção ultrapassada, biológica, de raça. Andando, desse modo, na contramão dos esforços do próprio Telles e de sua equipe, bem como das ciências sociais que buscam estudar raça como fenômeno sociológico - leais a seu compromisso antirracista e contra a naturalização da realidade social (cf. GuIMARÃEs, 2015). Embora possa parecer exagerada, a ressalva é pertinente em face de recentes aproximações a uma ideia naturalizada de "cor da pele", mesmo que da parte de um teórico insuspeito (cf. BANTON, 2012), e em face da importância crescente da genética, que não está isenta de adquirir conotações eugênicas e raciais (cf. Duster, 2003).

No entanto, a paleta de cores, do modo como foi habilmente empregada, tem uma grande virtude. Pigmentocracia, ideia emprestada de uma obra do antropó- 
logo chileno Alejandro Lipschutz, é mais do que um título. É uma hipótese sobre a estrutura das desigualdades e da hierarquia social nos países latino-americanos. Os dados de Telles e sua equipe mostram que por trás das categorias raciais existe, em todos os países estudados, uma escala de cor em que os indivíduos de pele mais clara têm inequivocamente melhor situação socioeconômica que os de pele mais escura, estando os indivíduos de tons de pele intermediários previsivelmente no meio. Mais uma vez, para os países hispano-falantes essa revelação tem mais impacto. No México, por exemplo, os dados da pesquisa apontam que os autodeclarados mestizos têm nível de escolaridade (um indicador de status socioeconômico) mais alto que os brancos e que os indígenas. Mas os dados de "cor" da paleta revelam no mesmo quesito uma escala que simplesmente vai do mais claro ao mais escuro, ao contrário do que a identificação categorial faz acreditar. Efeitos semelhantes ocorrem na Colômbia e no Peru. Telles conclui que os "dados sobre cor da pele mostram uma inequívoca pigmentocracia e sugerem que dados étnico-raciais baseados em auto-identificação são menos confiáveis do que a avaliação externa, e especialmente a cor, ao abordar a desigualdade étnico-racial” (p. 225). Uma proposição forte que provavelmente será muito debatida.

A hipótese pigmentocrática, digamos, bem como os dados que a sustentam, é revolucionária para o modo como se concebe e discute o tema na América Latina. Os quatro países estudados fizeram, há cerca de duas décadas, transições constitucionais que ajudaram a virar a página das ideologias de integração nacional pela mestiçagem em direção a modelos multiculturalistas de sociedade. Mas o Brasil, o mais estudado dos países latino-americanos no que tange ao tema, e sobre o qual assentam muitas das generalizações sobre a região, é uma exceção, nota Telles. Apenas aqui foram conquistadas políticas afirmativas consistentes para combater desigualdades raciais, o que sugere que o processo político de desconstrução de nossa imagem como democracia racial encontra-se em estágio avançado (cf. TeLLEs, 2004). Os dados do PERLA podem estimular os demais países a se deslocarem nessa direção.

Além disso, a visão corrente dos brasileiros acerca das divisões étnico-raciais é bastante alinhada com a hipótese pigmentocrática. O capítulo sobre Brasil mostra que a "desigualdade categorial" tem mais ou menos a mesma configuração que a "desigualdade contínua" (medida pela escala de cores), nos termos em que os autores resumem suas descobertas. Isto é, ao contrário do que acontece, em geral, nos demais países latino-americanos estudados, no Brasil a auto-identificação racial por meio das categorias usualmente utilizadas nas pesquisas oficiais (branco, pardo, preto, indígena, amarelo e outros) corresponde ao padrão esperado segundo 
a hipótese pigmentocrática: uma hierarquia que, em linhas gerais, vai dos indivíduos de pele mais clara aos de pele mais escura. Para além do aspecto ordinal, a pesquisa mostra também que, comparadas auto-identificação e categorização externa por meio da paleta de cores, existe no Brasil, para todas as categorias principais (branco, pardo e preto), entre 80\% e 90\% de consistência. Isso sugere, seguindo Guimarães, que a cor da pele é um dos aspectos essenciais da categorização racial corrente na sociedade brasileira (cf. Guimarães, 2012). A pesquisa confirma a permanência histórica e a pertinência atual das categorias de raça ou cor utilizadas nos censos no Brasil, assim como corrobora a precisão dessas mesmas categorias para descrever a estrutura social racializada de nosso país.

Por falar em precisão, outra descoberta substancial deve ser destacada. Os autores do capítulo sobre o Brasil, Marcelo Paixão e Graziella Moraes Silva, põem à prova suposições e hipóteses clássicas à luz dos dados do PERLA - procedimento que Telles levara às melhores consequências no clássico Racismo à brasileira [Race in another America]. Paixão e Silva abordam a polêmica sobre se o modo de medir raça nas estatísticas oficiais (auto-declaração segundo categorias definidas) leva a superestimar desigualdades raciais. A lógica é simples, e segue o ditado segundo o qual "o dinheiro embranquece”: "se os negros mais instruídos tendem a se branquear, as desigualdades raciais medidas por heteroclassificação [como na paleta de cores] seriam menores do que aquelas encontradas pelas estatística oficiais" (p. 202). A conclusão de Pigmentocracies vai no sentido oposto e mostra que a desigualdade é, atualmente, subestimada nas estatísticas que se baseiam em auto-classificação. O que sugere, ao contrário do dito popular, que os negros mais instruídos tendem a se declarar "pretos" (e, portanto, mais escuros,) com mais frequência do que os menos instruídos.

Encerrar com um problema só atesta a fecundidade do livro. A hipótese pigmentocrática escancara uma importante diferença entre o Brasil e os demais países latino-americanos: embora todos tenham se mantido "pigmentocráticos" ao longo do século XX, e assim permaneçam neste início de século XXI, no Brasil não vingou, a ponto de se tornar a mais significativa, uma categoria racial de integração nacional de cunho homogeneizante - tal como a categoria mestizo. Os mais privilegiados continuam a se declarar "brancos" e a se ver como tais, não importando se, em situações pontuais e de modo não raro cínico, gostem de afirmar que têm "um pé na cozinha”. A resiliência da branquidade não sugeriria que, ao contrário do que diz nossa narrativa nacional clássica - reproduzida em inúmeros estudos acadêmicos -, o triunfo e a hegemonia da ideologia da democracia racial teriam sido aqui apenas parciais? A última obra de Barbara Weinstein, sobre o desen- 
volvimento de uma ideologia regional "branca" precisamente nos anos daquela suposta hegemonia, desafia-nos a perseguir essa sugestão (cf. WEInstein, 2015).

\section{REFERÊNCIAS BIBLIOGRÁFICAS}

Banton, Michael. The color line and the color scale in the twentieth century. Ethnic and Racial Studies, vol. 35, n. 7, p. 1109-1131, 2012.

Duster, Troy. Backdoor to eugenics. New York and London: Routledge, 2003.

Guimarães, Antonio Sérgio. The Brazilian system of racial classification. Ethnic and Racial Studies, vol. 35, n. 7, p. 1157-1162, 2012.

. "Sociologia e natureza: classes, raças e sexos". São Paulo: mimeo, 2015.

Loveman, Mara. National colors: racial classification and the state in Latin America. Oxford and New York: Oxford University Press, 2014.

TELLEs, Edward. Race in another America: the significance of skin color in Brazil. New Jersey: Princeton University Press, 2004.

WeInSTEIn, Barbara. The color of modernity: São Paulo and the making of race and nation in Brazil. Durham and London: Duke University Press, 2015. 